\title{
Pengambilan contoh biologi secara noninvasif untuk penilaian status reproduksi pada landak jawa (Hystrix javanica)
}

\author{
Muhammad Risman Wahid ${ }^{1}$, Andhika Yudha Prawira ${ }^{1}$, Chairun Nisa, ${ }^{1}$, Srihadi Agungpriyono ${ }^{1}$, \\ Mokhamad Fakhrul Ulum ${ }^{2}$,* \\ ${ }^{1}$ Departemen Anatomi, Fisiologi, dan Farmakologi, Fakultas Kedokteran Hewan, Institut Pertanian Bogor, Jawa Barat \\ ${ }^{2}$ Departemen Klinik, Reproduksi, dan Patologi, Fakultas Kedokteran Hewan, Institut Pertanian Bogor, Jawa Barat
}

ABSTRAK: Landak jawa (Hystrix javanica) memiliki keunikan pada rambutnya yang termodifikasi menjadi duri. Duri pada landak berperan sebagai pertahanan diri dari predator. Penanganan dan pengekangan landak cukup sulit dilakukan sehingga pengambilan data biologi ladak jawa menjadi terbatas. Penanganan dan pengekangan secara kimiawi menggunakan sediaan bius umum digunakan pada hewan liar. Studi ini menggambarkan metode penanganan dan pengekangan fisik untuk pengambilan contoh biologi secara noninvasif pada landak jawa (H. javanica). Penggunaan kandang jepit yang dimodifikasi dengan penambahan sekat bergerak berbahan logam pada bagian dalam efektif untuk penanganan dan pengekangan landak jawa. Data biologi dari landak jawa yang dapat diambil untuk menilai status reproduksi dengan metode tersebut meliputi gambaran sel epitel vagina dan suhu tubuh.

Kata kunci:

Landak jawa, penanganan, pengekangan, contoh biologi, status reproduksi

\section{- PENDAHULUAN}

Landak jawa (Hystrix javanica) merupakan satwa liar endemik Indonesia. Hewan ini tergolong mammalia unik yang memiliki duri sebagai sistem pertahanan (Myers et al. 2017). Data biologi landak jawa saat ini masih sangat minim. Hal ini karena penanganan landak jawa cukup selit dilakukan. Berbeda dengan hewan domestik, penanganan untuk pengambilan data biologis pada hewan liar, umumnya dilakukan dengan menggunakan obat bius (Fowler 2008). Pemberian obat bius untuk keperluan pengambilan data biologis secara rutin pada hewan tidak dapat dilakukan. Penggunaan obat bius secara rutin dapat menyebabkan kegagalan fungsi hati, jantung (Araujo et al. 2014) dan penurunan fungsi otak (Stratmann 2011). Studi ini menjelaskan metode penanganan dan pengekangan untuk pengambilan biologi landak jawa.

\section{- BAHAN DAN METODE}

Bahan: Studi ini menggunakan 2 ekor landak betina, kandang jepit 45×26×26 cm (Gambar 1), pipet tetes pastik (pipet pasteur), cotton swabs, termometer suhu badan, kaca objek, larutan $\mathrm{NaCl}$, pewarna giemsa, dan metanol. Desain kandang: Kandang jepit dibuat dari bahan logam besi. Kandang didesain memiliki 2 (dua) pintu depan dan belakang. Bagian dalam memiliki pembatas (sekat) tambahan yang dapat digerakkan pada sisi atas dan bagian sisi bawah sebagai porosnya (Gambar 1).

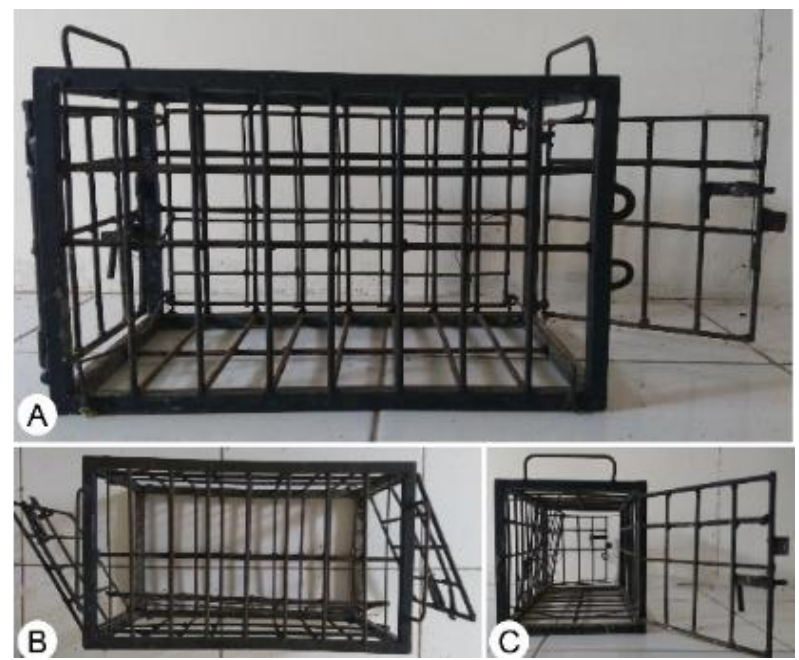

Gambar 1 Kandang jepit untuk proses penanganan dan pengekangan fisik. Tampak samping (A), tampak atas (B), dan tampak depan (C).

Metode: Landak jawa diumpan dengan makanan (dalam hal ini dapat menggunakan jagung) agar masuk ke dalam kandang jepit (Gambar 2A). Pintu masuk segera ditutup sesaat setelah landak masuk kedalam kandang jepit. Pengekangan dilakukan dengan menarik sekat besi bergerak yang berada dibagian dalam kandang jepit sehingga landak tertahan pada sisi. Kandang jepit yang berisi landak

Diterima: 11-06-2018 | Direvisi: 21-07-2018 | Disetujui: 28-07-2018 (C) 2018 CC-BY-SA. Ini adalah artikel Open Access yang didistribusikan berdasarkan ketentuan dari Creative Commons Attribution ShareAlike 4.0 Inter national License (https://creativecommons.org/licenses/by-sa/4.0/). 
kemudian ditempatkan miring dengan sudut $45^{\circ}$. Penggambilan data biologis selanjutnya dilakukan berupa flushing saluran reproduksi, ulas vagina dan pengukuran suhu daerah vulva maupun rektum.

Flushing dilakukan menggunakan pipet tetes pastik berisi larutan $\mathrm{NaCl}$ fisiologis \pm 5 -7 tetes, kemudian dimasukkan ke daerah vagina landak jawa (Gambar 2B). Hasil flushing disedot dan diteteskan ke kaca objek untuk diratakan. Preparat dibiarkan mengering, kemudian difiksasi dengan metanol dan diwarnai dengan giemsa. Ulas vagina dilakukan dengan cotton swabs baby yang dibasahi dengan larutan $\mathrm{NaCl}$ fisiologis. Cotton swab kemudian diulas kebagian dinding vagina landak jawa (Gambar 2C). Hasil ulas direkatkan ke permukaan kaca objek dan difiksasi dengan metanol serta diwarnai dengan giemsa. Suhu daerah vulva diambil menggunakan termometer suhu tubuh yang dimasukkan ke daerah vulva (Gambar 2D).

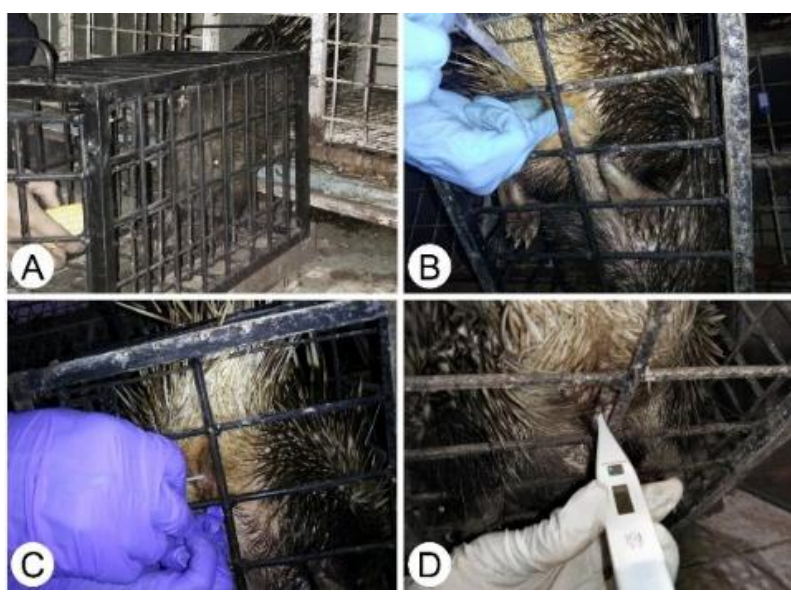

Gambar 2 Memasukkan landak ke dalam kandang jepit (a), pengambilan flushing (b), pengambilan ulas vagina (c), dan pengambilan suhu daerah vulva (d)

\section{- HASIL DAN PEMBAHASAN}

Penggunaan kandang jepit modifikasi yang dilengkapi sekat bergerak berbahan besi di bagian dalam dapat mengekang landak jawa. Metode ini memudahkan untuk pengambilan contoh biologis secara non invasif tanpa penggunaan sediaan bius. Data biologi yang dapat diambil untuk menilai status reproduksi meliputi gambaran sel epitel vagina dan suhu tubuh.

Gambar 3 menunjukkan hasil pengambilan contoh dengan flashing dan ulas vagina. Metode ini berhasil mendapatkan gambaran epitel membran vagina landak jawa. Gambaran sitologi vagina landak jawa menunjukan adanya sejumlah sel epitel yang terkornifikasi. Meningkatnya sel-sel epitel vagina yang mengalami kornifikasi menunjukan gejala estrus pada suatu hewan (Eurell and Frappier 2006). Hystrix africaeaustralis yang hidup di penangkaran mengalami siklus estrus yang bervariasi antara 17-42 hari (van Aarde 1985), sedangkan pada landak Atherurus africanus memiliki panjang siklus 27 hari (Mayor et al. 2003). Peningkatan dan penurunan suhu tubuh pada betina secara normal dapat berkolerasi dengan status reproduksinya. Peningkatan suhu tubuh ini dapat disebabkan karena adanya kenaikan hormon estrogen selama fase estrus atau hormon progesteron saat kebuntingan (Buxton and Atkinson, 1948).

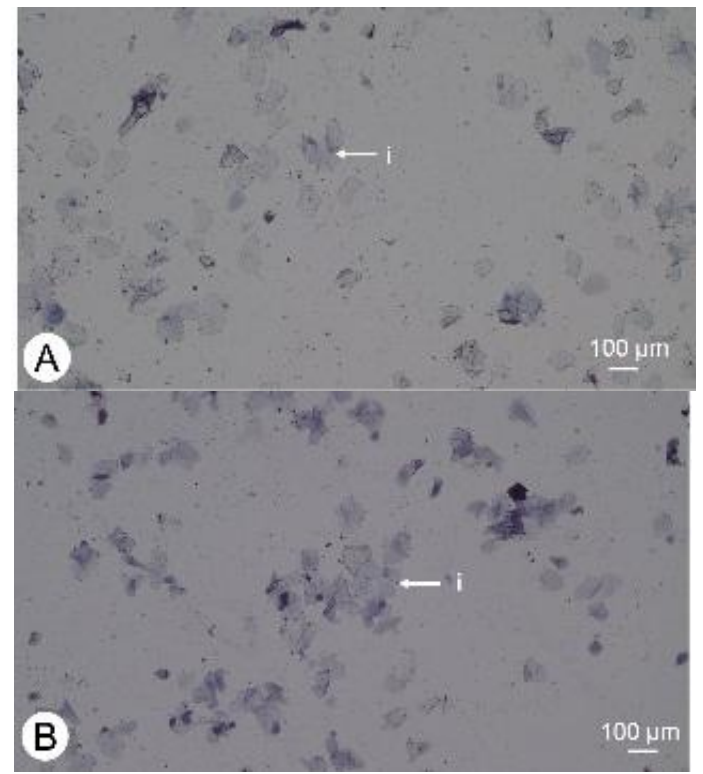

Gambar 3 Gambaran sitologi vagina landak jawa ditemukan adanya sel-sel intermediet (i). Flushing (A) dan ulas vagina (B).

\section{- SIMPULAN}

Penggunaan kandang besi yang modifikasi dengan sekat bergerak di bagian dalam efektif dalam penanganan dan pengekangan landak jawa untuk pengambilan data biologis.

\section{- INFORMASI PENULIS}

Penulis untuk Korespondensi

*MFU: ulum@ipb.ac.id

Departemen Klinik Reproduksi dan Patologi, Fakultas Kedokteran Hewan, Institut Pertanian Bogor, Jalan Agatis Kampus IPB Dramaga Bogor Jawa Barat 16680.

\section{- PUSTAKA ACUAN}

van Aarde RJ. 1985. Reproduction in captive female Cape porcupines (Hystrix africaeaustralis). J Reprod Fert. 75:577-582.

Araujo MA, Dias BP, Bovino F, Deschk M, Abimussi CJX, Oliva VNLS, Rodrigues CA, Santos PSP. 2014. Cardiovascular effects of a continuous rate infusion of lidocaine in calves anesthetized with xylazine, midazolam, ketamine and isoflurane. Vet Anaesth Analg. 41:145-152.

Buxton CL, Atkinson WB. 1948. Hormonal factor involved in the regulation of basal body temperatuure during the menstrual sycle and pregnancy. Obstet. Gynecol. Surv. 8, 544-549.

Eurell JA, Frappier BL (eds). 2006. Dellmann's Textbook of Veterinary Histology. Blackwell Publishing: Australia.

Fowler ME. 2008. Restraint and Handling of Wild and Domestic Animal. Wiley-Blackwell: State Avenue.

Mayor P, López-Béjar M, Jori F, Fenech M, López-Gatius F. 2003. Reproductive functional anatomy and oestrous cycle pattern of the female Brush-tailed porcupine (Atherurus africanus, Gray 1842) from Gabon. Anat Histol Embryol. 77(3-4):247-259.

Myers P, Espinosa R, Parr CS, Jones T, Hammond GS, Dewey TA. 2017. The animal diversity web Available at: http://animaldiversity.org. [Accessed 8 January 2018]

Stratmann G. 2011. Neurotoxicity of anesthetic drugs in the developing brain. 113(5):1170-1179. 